\title{
Changes in nutritional status and associated factors in a geriatric post-hip fracture assessment
}

\begin{abstract}
Aim: To examine changes in nutritional status and to identify factors associated with poor nutritional status in a comprehensive geriatric assessment after hip fracture.

Methods: Nutritional status according to the M ini Nutritional Assessment Short Form (M NA-SF) was assessed in 585 hip fracture patients aged 65 years and over at baseline and six months postoperatively at our geriatric outpatient clinic. Poor nutritional status was defined as being malnourished or at risk of malnutrition according to the MNA-SF. Logistic regression analyses were used.
\end{abstract}

Results: At baseline 39\% and at follow-up 59\% of patients had poor nutritional status. After adjusting for age, higher age, American Society of Anesthesiologists (ASA) -grade 3, taking 4-10 medications, prefracture diagnosis of memory disorder, non-independent mobility, not living in own home and poor nutritional status at baseline were prognostic factors for poor nutritional status. In the geriatric assessment, MMSE $<4$, difficulties in basic activities of daily living, depressive mood, longer time on Timed Up and Go (TUG) and weakened grip strength were associated with poor nutritional status. In multivariate analyses, prefracture memory disorder, MNA-SF at baseline and depressive mood, TUG and grip strength in the outpatient assessment continued to be associated with poor nutritional status at follow-up.

Conclusions: Cognition and mood require attention in the nutritional care of hip fracture patients. The strong association of poor nutritional status with impaired mobility and grip strength implies an association between protein-energy malnutrition and sarcopenia. Both muscle strength and nutrition need to be addressed in comprehensive hip fracture care and rehabilitation.

Keywords: nutrition, hip fracture, comprehensive geriatric assessment, frailty 


\section{Introduction}

The prevalence of malnutrition is very high in older populations. This has been demonstrated in many healthcare settings, hospitals and among community dwelling older people [1-4]. The incidence of hip fracture is currently high and expected to increase, especially in women, due to population aging [5]. $M$ alnutrition is one significant risk factor for falls and fractures [6]. Food intake is often insufficient during recovery from the hip fracture operation, impairing the nutritional status further [7]. Patients with protein-energy malnutrition have a higher postoperative complication rate, which means longer expensive hospital stay, and also higher morbidity and mortality [4,7-9]. Altogether individuals with malnutrition are more likely to experience poor quality of life $[1,10]$. Identifying patients likely to benefit from nutritional support could reduce morbidity and mortality and also save costs.

Nutritional screening is important in order to identify at-risk patients. There is no gold standard for assessing nutritional status. The short form of the M ini Nutritional Assessment (M NA-SF) is one of the most frequently used nutritional instruments to assess nutritional status in older hip fracture patients. Both malnutrition and risk of malnutrition as assessed by the M NA-SF have recently been proven to predict major negative outcomes in older hip fracture population [3].

So far only very few studies have examined changes in nutritional status in older populations over time $[11,12]$. To the best of our knowledge, no population-based observational studies have been presented following up changes in nutritional status in older hip fracture patients. The aim of the present study was to follow up nutritional status as measured by the MNA-SF [13] from the time of the hip fracture to the comprehensive geriatric outpatient assessment, to which all the hip fracture patients in our hospital were invited, according to our local care pathway, 4-6 months after the fracture. In particular, we aimed to identify prefracture prognostic indicators of poor nutritional status and factors associated with poor nutritional status as assessed at the outpatient clinic.

\section{Material and methods}

\subsection{Study population and design}

The study includes all 1,025 consecutive patients aged over 65 who suffered their first hip fracture between January 2010 and December 2014. Pathological fractures were excluded. Of the patients $88 \%$ were operated on within 48 hours of admission to our hospital. The mean length of stay in the hospital was six days. Seinäjoki Central Hospital, Finland is the only hospital in the Southern 
Ostrobothnia region providing acute surgical care. The population of the hospital district is approximately 200,000 and all hip fractures are treated there.

The nurses on the orthopaedic ward were instructed to give daily nutritional supplements rich in energy (300 kcal) and protein ( $20 \mathrm{~g})$ twice a day to all hip fracture patients in addition to meals (breakfast, lunch, dinner and evening snack) enriched with energy and protein. It was recommended to continue this in the primary care hospitals where patients were transferred for rehabilitation.

\subsection{Data collection}

The baseline data were collected during the perioperative hospital stay mainly by a single geriatric nurse interviewing the patients or their representatives and by extracting it from hospital records. In addition, data were collected during the visit to the geriatric outpatient clinic in the comprehensive assessment in a median time of six months (Inter Quartile Range [IQR] 4-6 months) after the fracture. A physiotherapist's examination preceded the geriatric assessment. All the patients or their caregivers gave informed consent and the study design was approved by the ethics committee of our hospital district. The dates of death for mortality follow-up were extracted from the electronic patient files. The mortality data were complete.

\subsection{Variables}

In order to assess the nutritional status MNA-SF was used in the perioperative period on the orthopaedic ward and again at the outpatient clinic. To measure the body mass index (BMI), the patients' height and weight were monitored as reported by the patients or caregivers or extracted from the patient files and, if not available, as estimated by the nurses on the orthopaedic ward. At the outpatient clinic the patients were measured and weighed. The MNA-SF consists of six sections: appetite or eating problems, recent weight loss, mobility impairment, acute illness/stress, dementia or depression and BMI. Its scores are 0-7 points malnourished, 8-11 points at risk of malnutrition and 1214 points normal nutritional status [13]. For the purposes of our study, poor nutritional status was defined as being at risk of malnutrition or being malnourished according to the M NA-SF.

The preoperative American Society of Anesthesiologists (ASA) risk scores were used to assess general health at the time of the fracture. There are five classes: 1) healthy person, 2) mild systemic disease, 3) severe systemic disease, 4) severe systemic disease that is a constant threat to life and 5) a moribund person who is not expected to survive without the operation [14]. The ASA scores were categorized into three groups: $1-2,3$ or 4-5.

A possible diagnosis of memory disorder was elicited at the time of the fracture and defined as a clinical diagnosis confirmed by a specialist in geriatric medicine or in neurology. 
The baseline independent mobility was defined as being able to move independently without personal assistance. Living in an institution was defined as residing in a health centre hospital or residential care home providing 24-hour care.

In the comprehensive geriatric assessment (CGA), the Geriatric Depression Scale (GDS-15) was used to measure the individual's mood [15]. The GDS-15 consists of 15 questions with higher scores indicating more symptoms of depression, a cut-off score of six meaning depressive mood. Cognition was assessed by the Mini M ental State Examination (M MSE), where a score of less than 24 points out of 30 was considered to indicate cognitive impairment [16]. Difficulties in the basic activities of daily living (ADLS) were defined as having difficulties in at least one out of the six basic activities of daily living [17] and difficulties in instrumental activities of daily living (IADL) one out of the eight IADLs [18]. The patients' regular medications were categorized as less than 4, 4-10 or more than 10 regular daily medications.

Physical functioning tests were conducted by a physiotherapist. Grip strength was measured using the Jamar Dynamometer on both the right and left hands. In men, grip strength less than $26 \mathrm{~kg}$ and in women less than $16 \mathrm{~kg}$ in the stronger hand was defined as weakened [19]. The Timed Up and Go test (TUG) requires patients to stand up from a chair, walk a short distance, turn around, return and sit down again [20]. It assesses both mobility and fall risk. In addition to measuring the median time, the performance on the TUG was categorized as normal (1 point), slightly abnormal (2-4 points) or markedly abnormal (5 points) as evaluated by mainly the same physiotherapist. Three or more points mean risk of falling. The Elderly M obility Scale (EMS) was used to evaluate an individual's mobility problems in seven functional activities including bed mobility, transfers and bodily reaction to perturbation, speed of going from sitting to standing and walking speed [21]. The tasks give 0-4 points, total 20 . Scores over 14 are taken to mean independent in basic ADLS.

\subsection{Statistical analysis}

Distributions of the basic characteristics at baseline between the well-nourished, those at risk of malnutrition and the malnourished are described in Table 1. Differences in the distribution of age, gender, ASA scores, BMI, M NA, type of hip fracture, regular medications and length of stay in hospital, mobility and living arrangements between groups were analysed by independent samples KruskallWallis test or Pearson chi-square test. Due to the skew distributions, continuous variables were described by medians, with ranges and modelled by non-parametric tests.

Age-adjusted prognostic factors of poor nutritional status at baseline and in the CGA after six months' follow-up were calculated by logistic regression. The results were shown as prevalence odds ratios (POR) or incidence odds ratios (IOR) with 95\% confidence intervals (CI). Finally, multivariate analyses including all the factors examined as enter and forward and backward stepwise models were conducted. 
Statistical analyses were performed with IBM SPSS Statistics for Windows, version 20.0.0 (IBM Corp. Released 2011, Amonk, NY). The p-value $<0.05$ was considered statistically significant.

\section{Results}

Before the exclusions 493 (51\%) out of 958 patients had normal nutritional status, 388 (41\%) were at risk of malnutrition and 77 (8\%) were malnourished. The MNA scores were missing in 67 cases, mainly due to inconsistent data during initiation of nutritional assessment. After six months' follow-up, the M NA points scores were missing due to non-attendance in 191 cases and 182 patients had died, so the final sample size was 585 (Figure 1). After six months 63 (11\%) patients had better nutritional status and in 205 (35\%) patients the nutritional status had deteriorated (Figure 1). Of the 585 patients, 227 (39\%) were at risk of malnutrition or malnourished according to M NA-SF at baseline and $346(59 \%)$ at follow-up (Table 2). At baseline the median of points in M NA-SF was 13 (IQR and Range 12-14) in normal nutritional status and 10 (IQR 8-11, Range 2-11) in poor nutritional status, and after follow-up 12 (IQR 10-13, Range 2-14) in normal nutritional status and 10 (IQR 8-11, Range 1-14) in poor nutritional status. The change in normal nutritional status was M d -1 (IQR -3 -0; range -11-2) and in poor nutritional status Md 0 (IQR -2-2; range -8-8).

Compared to the attendees of the geriatric outpatient assessment, the non-attendees and deceased were older; they had higher ASA scores, were taking more regular medications and had lower BMI and M NA scores (Supplementary Table). In the baseline age-adjusted univariate analyses (Table 2) all the domains except the type of fracture and the time to the operation were associated with poor nutritional status. The baseline prognostic indicators of poor nutritional status at follow-up were high age, ASA score 3, diagnosis of memory disorder, non-independent mobility, living in an institution, taking more than four regular medicines per day and poor nutritional status at baseline.

The factors associated in the aged-adjusted univariate analyses with poor nutrition in the CGA were cognitive impairment, depressive mood, basic ADLs and IADLs, abnormal result in the TUG-test (either as time or as categorized by the examining physiotherapist) and weakened grip strength (Table 3). When using the multivariate analysis by enter model, diagnosis of memory disorder OR $2.45(95 \% \mathrm{Cl}$ 1.23-4.87), MNA at baseline OR 2.10 (95\% Cl 1.25-3.51), GDS-15 OR 2.38 (95\% Cl 1.20-4.70), TUG time OR 1.04 (95\% Cl 1.01-1.07) and grip strength OR 2.00 (95\% Cl 1.25-3.21) at follow-up continued to be associated with poor nutritional status. The forward and backward stepwise models gave the same results. 


\section{Discussion}

The findings of our study demonstrate that poor nutritional status is very common among older hip fracture patients, which concurs with the literature [2-4,9]. The observations could be explained by patients' poor appetite after the trauma and operation and less than recommended dietary intake [7]. There was a clear deterioration in nutritional status between the time of the fracture and follow-up. Nutritional status improved in only few patients during the rehabilitation period. Even patients with normal nutritional status were prone to develop risk of malnutrition. Deterioration of nutritional status has previously been reported in hospitalized older patient populations [22], and bed rest is a wellknown cause of loss of skeletal muscle [23]. The negative findings may reflect the poor rehabilitation outcomes of older hip fracture patients that have been reported in numerous studies [24]. Moreover, perioperative medical complications and dementia has been found to restrict nutritional intake [25]. Even in the present study, poor nutritional status was predicted by prefracture diagnosis of memory disorder. The patients whose nutritional status deteriorated were older and had higher comorbidity scores and more cognitive impairment and depressive mood. These findings are in accord with previous reports $[4,9,25,26]$.

About two thirds of the patients with poor nutritional status had difficulties in the basic ADLs and IADLs. Similar results have been published before [2]. Over half of the patients had abnormal results on the in TUG test and weakened grip strength. In an earlier study hand grip strength has been found to correlate with nutritional status $[27,28]$.

Physical function, gait speed and cognition have been the most commonly used criteria for identifying components of frailty [29]. Sarcopenia has been defined as progressive loss of skeletal muscle mass, strength and power and is considered a significant component of frailty [30]. In our study in the multivariate analysis, longer time on the TUG test, weakened grip strength, memory disorder, depressive mood and poor nutrition at baseline were independent prognostic indicators of poor nutritional status at follow-up. Bollwein and colleagues reported a similar association between frailty syndrome and poor nutritional status [31].It has to be noted that physical performance, cognition and mood are in fact domains that are included as parameters in the MNA-SF and this may have in part affected the associations of these domains with poor nutritional status. Nevertheless, the observations do emphasize the significance for a comprehensive approach to nutritional care. Patients with cognitive impairment and memory disorders need specific attention and taking care of the patients' mood is also a priority. The association between poor nutritional status and impaired mobility and weakened grip strength suggests an association between protein-energy malnutrition and sarcopenia. This underlines the importance of exercises aimed at improving muscle strength in combination with effective nutritional care. 
The strengths of our study include a large and representative study population, prospective and consecutive design, and the use of well-known and standardized instruments in the comprehensive geriatric assessment. Due to the good coverage of our systematic data collection, basic baseline information and mortality dates were available even for patients who did not attend the outpatient clinic. The data were collected mainly by a single geriatric nurse and the tests of physical functioning by mainly the same physiotherapist, which strengthens the reliability of the data. Patients were not excluded from the investigation on the basis of any comorbidity, for example having a memory disorder or living in an institution.

There are number of limitations to our study. First, hip fracture patients' weight and height are difficult to measure in the perioperative period because of pain. On the other hand height and weight were estimated again at the outpatient clinic and at that time the patients were also measured. These two BMI results were very near each other, which means that the estimates were fairly accurate. It is worth noting that measuring the height as a part of the BMI may be unreliable, especially in older frail female patients, due to possible shortening of the spine attributed to vertebral fractures [32]. On the other hand muscle mass decreases as people age. Thus aging affects BMI less than weight and height [33].

The second limitation was that exception of nutritional status, the rest of the domains of the CGA were not examined at the time of the fracture, and thus it was not possible to examine changes in these domains between baseline and follow-up. Third, follow-up data were available on $57 \%$ of the original hip fracture cohort. According to our analyses, patients in poorest health had either died or were not able to attend the outpatient clinic. This may impair the reliability of the data introducing a possibility of a selection bias, where the number of undernourished people is likely to be underestimated. Finally, the present study was a real-life observational and non-interventional study and thus, in spite of the instructions given to the nurses regarding nutritional care and supplementation, the effect of these practices on the outcomes could not be examined.

\section{Conclusions}

It is very important to pay attention to hip fracture patients' nutritional status with supplements and energy and protein-rich meals during the acute phase of hip fracture care and in the course of rehabilitation. M alnutrition predisposes to muscle weakness, additional illnesses and falls. Age, comorbid conditions, prefracture functional and mental abilities, and nutritional status have an impact on the outcome regarding ambulation, activities of daily living and quality of life. Comprehensive geriatric care by means of orthogeriatric management and multidisciplinary geriatric rehabilitation both based on the gold standard of CGA - need to be implemented more actively to improve the outcomes of geriatric fracture patients and also to save costs. Nutritional assessment and interventions 
constitute an essential component of the CGA. It is likely that the same principles also apply to other frail acutely ill hospitalized patients in different medical specialities.

\section{ACKNOWLEDGEM ENTS}

M s Kaisu Haanpää, RN, is gratefully acknowledged for her expert collection of the data and performing the M NAs, likewise Ms Anneli Risku, physiotherapist, for carefully carrying out the physical performance tests on the patients. This study was financially supported by the State Research Financing of Seinäjoki Central Hospital.

\section{LEGEND}

Figure 1. Flow chart of nutritional status according to MNA-SF in the study population. 


\section{References}

[1] van-Bokhorst-de van der Schauren M , Lonterman-M onasch S, de Vries O, Danner S, Kramer M, Muller M. Prevalence and determinants for malnutrition in geriatric outpatients. Clin Nutr 2013;32:1007-11

[2] Goisser S, Schrader E, Singler K, Bertsch T, Gefeller O, Biber R, et al. M alnutrition According to M ini Nutritional Assessment is Associated with Severe Functional Impairment in Geriatric Patients Before and up to 6 Months After Hip Fracture. J Am M ed Dir Assoc 2015;16:661-7

[3] Nuotio M, Tuominen P, Luukkaala T. Association of nutritional status as measured by the MiniNutritional Assessment Short Form with changes in mobility, institutionalization and death after hip fracture. Eur J Clin Nutr 2016;70:393-8

[4] Koren-Hakim T, Weiss A, Hershkovitz A, Otzrateni I, Grosman P, Frishman S, et al. The relationship between nutritional status of hip fracture operated elderly patients and their functioning, comorbidity and outcome. Clin Nutr 2012;31:917-21

[5] Chang K, Center J, Nguyen T, Eisman J. Incidence of Hip and Other Osteoporotic Fractures in Elderly Men and Women: Dubbo Osteoporosis Epidemiology Study. J Bone and Mineral Res 2004;19:532-6

[6] Stolee P, Poss ], Cook R, Byrne K, Hirdes ]. Risk Factors for Hip Fracture in Older Home Care Clients. J Gerontol A Biol Sci M ed Sci 2009;64A:403-10

[7] Goisser S, Schrader E, Singler K, Bertsch T, Gefeller O, Biber R, et al. Low postoperative dietary intake is associated with worse functional course in geriatric patients up to 6 months after hip fracture. Br J Nutr 2015;113:1940-50

[8] Nikkel L, Fox E, Black K, Davis C, Andersen L, Hollenbeak C. Impact of Comorbidities on Hospitalization Costs Following Hip Fracture. J Bone Joint Surg Am. 2012;94:9-17

[9] Drevet S, Bioteau C, M aziere S, Couturier P, M erloz J, Tonetti J, Gavazzi G. Prevalence of proteinenergy malnutrition in hospital patients over 75 years of age admitted for hip fracture. Orthop Traumatol Surg Res. 2014;100:669-74

[10] Rasheed S, Woods R. An investigation into the association between nutritional status and quality of life in older people admitted to hospital. J Hum Nutr Diet 2014;27:142-51

[11] Izawa S, Enoki H, Hasegawa J, Hirose T, Kuzuya M. Factors associated with deterioration of mini nutritional assessment-short form status of nursing home residents during a 2-year period. J Nutr Health Aging 2014;18:372-7

[12] Collins ], Porter J, Truby H, Huggins C. How does nutritional state change during a subacute admission? Findings and implications for practice. Eur J Clin Nutr 2016;70:607-12

[13] Rubenstein L, Harker J, Salva A, Guigoz Y, Vellas B. Screening for Undernutrition in Geriatric Practice: Developing the Short-Form M ini-Nutritional Assessment (M NA-SF). J Gerontol A Biol Sci Med Sci. 2001; 56:366-72 
[14] Sankar A, Johnson S, Beattie W, Tait G, Wijeysundera D. Reliability of the American Society of Anesthesiologists physical status scale in clinical practice. Br J Anaest 2014;113:424-32

[15] Brown L, Schinka J. Devolepment and initial validation of a 15-item informant version of the Geriatric Depression Scale. Int J Geriatr Psychiatry 2005;20:911-8

[16] Folstein M , Folstein S, M cHugh P. "M ini-mental state". A practical method for grading the cognitive state of patients for the clinician. J Psychiatr Res 1975;12:189-98

[17] Katz S, Akpom C. Index of ADL. Med Care 1976 M ay; 14(5 Suppl):116-8

[18] Lawton M, Brody E. Assessment of older people: self-maintaining and instrumental activities of daily living. Gerontologist 1969;9:179-86

[19] Alley D, Shardell M, Peters K, M cLean R, Dam T, Kenny A, et al. Grip Strength Cutpoints for the Identification of Clinically Relevant Weakness. J Gerontol A Biol Sci M ed Sci 2014;69:559-66

[20] M athias S, Nayak U, Isaacs B. Balance in elderly patients: the "get-up and go" test. Arch Phys Med Rehabil 1986;67:387-9

[21] Smith R. Validation and Reliability of the Elderly M obility Scale. Physiotherapy 1994;90:744-7

[22] Liang X, Jiang Z-M , Nolan M , Wu X, Zhang H, et al. Nutritional risk, malnutrition (undernutrition), Overweight, obesity and nutrition support among hospitalized patients in Beijing teaching hospitals. Asia Pac J Clin Nutr 2009;18:54-62

[23] Kortebein P, Ferrando A, Lombeida J, Wolfe R, Evans WJ. Effect of 10 days of bed rest on skeletal muscle in healthy older adults. JAM A 2007;25:1772-4.

[24]Dyer SM , Crotty M, Fairhall N, Magaziner ], Beaupre LA, Cameron ID et al. A critical review of the long-term disability outcomes following hip fracture. BM C Geriatrics 2016;Accessed 2 September.

[25] Foss N, Jensen P, Kehlet H. Risk factors for insufficient perioperative oral nutrition after hip fracture surgery within a multi-modal rehabilitation programme. Age and Ageing 2007;36:538-43

[26] Cabrera M, M esas A, Garcia A, de Andrade S. Malnutrition and depression among communitydwelling elderly people. J Am Med Dir Assoc 2007;8:582-4

[27] Kaburagi T, Hirasawa R, Yoshino H, Odaka Y, Satomi M, Nakano M, et al. Nutritional status is strongly correlated with grip strength and depression in community-living elderly Japanese. Public Health Nutr. 2011;14:1893-9

[28] Norman K, Stobäus N, Gonzalez M, Schulzke J, Pirlich M. Hand grip strength: outcome predictor and marker of nutritional status. Clin Nutr 2011;30:135-42

[29] Sternberg S, Wershof Schwartz A, Karunananthan S, Bergman H, Mark Clarfield A. The identification of frailty: a systemic literature review. J Am Geriatr Soc 2011;59:2129-38

[30] Cruz-Jentoft A, Baeyens ], Bauer ], Boirie Y, Cederholm T, Landi F, et al. Sarcopenia: European consensus on definition and diagnosis. Age and Aging 2010;39:412-23 
[31] Bollwein J, Volkert D, Diekmann R, Kaiser M, Uter W, Vidal K, et al. Nutritional status according to the mini nutritional assessment (M NA) and frailty in community dwelling older persons: a close relationship. J Nutr Health Aging 2013;17:351-6

[32] Wahlqvuist ML, Flint DM . Assessment of loss of height in elderly women. Eur ] clin Nutr 1988;42:679-82.

[33] Dey DK, Rothenberg E, Sundh V, Bosaeus I, Steen B. Height and body weight in the elderly. A 25year longitudinal study of a population aged 70 to 95 years. Eur J Clin Nutr 1999;53:905-14 
Table 1. Distribution of predictor variables at baseline according to the MNA-SF (N=958)

\begin{tabular}{|c|c|c|c|c|c|c|c|}
\hline \multirow[b]{2}{*}{ Age, Md (IQR, Range) } & \multicolumn{2}{|r|}{$\begin{array}{l}\text { Normal } \\
(n=493)\end{array}$} & \multicolumn{2}{|c|}{$\begin{array}{l}\text { At risk of malnutrition } \\
(\mathrm{n}=388)\end{array}$} & \multicolumn{2}{|c|}{$\begin{array}{l}\text { Malnourished } \\
(\mathrm{n}=77)\end{array}$} & \multirow{2}{*}{$\begin{array}{c}\mathrm{p} \\
<0.001\end{array}$} \\
\hline & 83 & $(76-87 ; 65-98)$ & 85 & $(73-95 ; 65-103)$ & 85 & $(74-90 ; 65-99)$ & \\
\hline Male, $\mathrm{n}(\%)$ & 150 & (30) & 82 & (21) & 22 & (29) & 0.006 \\
\hline BMI, Md (IQR) & 26.4 & $(22.5-40.7)$ & 24.2 & $(22-35.3)$ & 20.3 & $(17.4-27.2)$ & $<0.001$ \\
\hline MNA-SF before hip-fracture, Md ( Range) & 13 & $(12-14)$ & 10 & $(8-11)$ & 6 & $(2-7)$ & $<0.001$ \\
\hline Fracture type, n (\%) & & & & & & & 0.679 \\
\hline Neck of femur & 304 & $(62)$ & 238 & $(61)$ & 44 & $(57)$ & \\
\hline Intertrochanteric & 157 & $(32)$ & 127 & $(33)$ & 27 & $(35)$ & \\
\hline Subtrochanteric & 30 & (6) & 23 & (6) & 6 & $(8)$ & \\
\hline ASA, n $(\%)$ & & & & & & & $<0.001$ \\
\hline $1-2$ & 100 & $(21)$ & 34 & $(9)$ & 3 & (4) & \\
\hline 3 & 315 & $(65)$ & 237 & (61) & 48 & (64) & \\
\hline $4-5$ & 71 & (14) & 115 & $(30)$ & 24 & $(32)$ & \\
\hline Missing & 7 & & 2 & & 2 & & \\
\hline Number of regularly taken medications, $\mathrm{n}(\%)$ & & & & & & & $<0.001$ \\
\hline$<4$ & 121 & $(25)$ & 48 & $(12)$ & 10 & (13) & \\
\hline $4-10$ & 297 & $(60)$ & 247 & (64) & 52 & (67) & \\
\hline over 10 & 72 & $(15)$ & 93 & (24) & 15 & (20) & \\
\hline Diagnosis of memory disorder, $\mathrm{n}(\%)$ & 82 & (16) & 158 & (41) & 29 & (38) & $<0.001$ \\
\hline Independent mobility, $\mathrm{n}(\%)$ & 367 & $(75)$ & 128 & (33) & 18 & $(23)$ & $<0.001$ \\
\hline Living in own home, $\mathrm{n}(\%)$ & 409 & (84) & 216 & (56) & 46 & $(60)$ & $<0.001$ \\
\hline Time to operation $<24 \mathrm{~h}, \mathrm{n}(\%)$ & 220 & $(45)$ & 145 & (38) & 32 & (43) & 0.185 \\
\hline Hospital stay, n (\%) & & & & & & & 0.797 \\
\hline 1-3 days & 30 & (6) & 25 & $(7)$ & 6 & $(8)$ & \\
\hline 4-5 days & 230 & (47) & 200 & (52) & 37 & (49) & \\
\hline 6-7 days & 158 & (31) & 106 & (28) & 22 & (29) & \\
\hline over 7 days & 67 & (14) & 51 & (13) & 10 & (13) & \\
\hline Missing & 8 & & 6 & & 2 & & \\
\hline
\end{tabular}

Md=Median; IQR=Interquartile range. Differences (p-value) between groups were tested by Independent samples Kruskall-Wallis test or Pearson chi-square test. 
Table 2 Age-adjusted indicators of poor nutritional status (at risk of malnutrition or malnourished) at baseline among hip-fracture patients ( $\mathrm{N}=585$ ).

\begin{tabular}{|c|c|c|c|c|c|c|c|c|c|c|c|}
\hline & \multirow[b]{2}{*}{$\mathrm{N}$} & \multicolumn{5}{|c|}{$\begin{array}{l}\text { Poor nutrition at baseline } \\
{[\mathrm{n}=227(39 \%)]}\end{array}$} & \multicolumn{5}{|c|}{$\begin{array}{l}\text { Poor nutrition at } 6 \text { months follow-up } \\
{[\mathrm{n}=346(59 \%)]}\end{array}$} \\
\hline & & $\mathrm{n}$ & $(\%)$ & $\mathrm{p}$ & POR & $(95 \% \mathrm{CI})$ & $\mathrm{n}$ & $(\%)$ & $\mathrm{p}$ & IOR & $(95 \% \mathrm{CI})$ \\
\hline Age & 585 & 227 & (39) & & 1.04 & $(1.01-1.06)$ & 346 & (59) & & 1.05 & $(1.03-1.08)$ \\
\hline Sex & & & & 0.005 & & & & & 0.050 & & \\
\hline Male & 443 & 41 & (29) & & 1.00 & & 74 & (52) & & 1.00 & \\
\hline Female & 142 & 186 & (42) & & 1.63 & $(1.07-2.47)$ & 272 & (61) & & 1.28 & $(0.86-1.89)$ \\
\hline Fracture type & & & & 0.421 & & & & & 0.126 & & \\
\hline Neck of femur & 373 & 139 & (37) & & 1.00 & & 211 & (57) & & 1.00 & \\
\hline Intertrochanteric & 182 & 74 & (41) & & 1.08 & $(0.75-1.56)$ & 119 & (65) & & 1.34 & $(0.92-1.94)$ \\
\hline Subtrochanteric & 29 & 14 & (48) & & 1.52 & $(0.71-3.26)$ & 16 & (55) & & 0.88 & $(0.41-1.93)$ \\
\hline ASA & & & & 0.001 & & & & & 0.009 & & \\
\hline $1-2$ & 114 & 27 & (24) & & 1.00 & & 52 & (46) & & 1.00 & \\
\hline 3 & 374 & 152 & (41) & & 1.97 & (1.21-3.23) & 231 & (62) & & 1.60 & $(1.03-2.48)$ \\
\hline $4-5$ & 90 & 45 & (50) & & 2.77 & (1.50-5.14) & 59 & (66) & & 1.76 & $(0.97-3.19)$ \\
\hline Not known & 7 & 3 & (43) & & 2.22 & $(0.46-10.7)$ & 4 & (57) & & 1.39 & $(0.29-6.65)$ \\
\hline Regular medications & & & & 0.008 & & & & & 0.007 & & \\
\hline$<4$ & 140 & 41 & (29) & & 1.00 & & 67 & (48) & & 1.00 & \\
\hline $4-10$ & 360 & 144 & (40) & & 1.57 & $(1.03-2.40)$ & 227 & (63) & & 1.81 & $(1.21-2.71)$ \\
\hline over 10 & 85 & 42 & (49) & & 2.29 & (1.30-4.02) & 52 & (61) & & 1.64 & $(0.94-2.86)$ \\
\hline Diagnosis of memory disoder & & & & $<0.001$ & & & & & $<0.001$ & & \\
\hline No & 431 & 131 & (30) & & 1.00 & & 213 & (49) & & 1.00 & \\
\hline Yes & 152 & 94 & (62) & & 3.60 & (244-5.31) & 131 & (86) & & 6.18 & (3.74-10.2) \\
\hline Missing & 2 & 2 & (100) & & & & 2 & (100) & & & \\
\hline Mobility* & & & & $<0.001$ & & & & & $<0.001$ & & \\
\hline Independent & 389 & 99 & (25) & & 1.00 & & 183 & (47) & & 1.00 & \\
\hline Non-independent & 195 & 128 & (66) & & 5.36 & (3.66-4.84) & 162 & (83) & & 5.06 & (3.29-7.77) \\
\hline Living & & & & $<0.001$ & & & & & $<0.001$ & & \\
\hline Home & 460 & 152 & (33) & & 1.00 & & 240 & (52) & & 1.00 & \\
\hline Institution & 122 & 73 & (60) & & 2.83 & (1.87-4.29) & 104 & (85) & & 4.89 & (2.86-8.36) \\
\hline Not known & 3 & 2 & (67) & & 3.85 & $(0.35-42.8)$ & 2 & (67) & & 1.68 & $(0.15-18.7)$ \\
\hline Time to operation & & & & 0.316 & & & & & 0.787 & & \\
\hline$<24 \mathrm{~h}$ & 258 & 92 & (36) & & 1.00 & & 149 & (58) & & 1.00 & \\
\hline$>24 \mathrm{~h}$ & 321 & 132 & (41) & & 1.21 & $(0.86-1.71)$ & 193 & (60) & & 1.04 & $(0.74-1.46)$ \\
\hline Not known & 6 & 3 & (50) & & 1.75 & $(0.34-9.05)$ & 4 & (67) & & 1.42 & $(0.25-8.19)$ \\
\hline MNA before hip-fracture & & & & & & & & & $<0.001$ & & \\
\hline Normal & 358 & & & & & & 162 & (45) & & 1.00 & \\
\hline At risk of malnutrition & 194 & & & & & & 153 & (79) & & 4.32 & (2.88-6.49) \\
\hline Malnourished & 33 & & & & & & 31 & (94) & & 17.6 & (4.14-75.1) \\
\hline
\end{tabular}

Age-adjusted univariate analyses were performed by logistic regression results shown by prevalence odds ratios (POR) or by incidence odds ratios (IOR) with $95 \%$ Confidence Intervals (CI). Statistically significant $(\mathrm{p}<0.05)$ odds ratios were bolded. * One missing case, normal nutrition. 
Table 3. Age-adjusted indicators of poor nutritional status (at risk of malnutrition or malnourished) after 6 months follow-up among hip-fracture patients $(\mathrm{N}=585)$.

\begin{tabular}{|c|c|c|c|c|c|c|}
\hline \multirow[b]{3}{*}{ MMSE } & \multirow[b]{2}{*}{$\mathrm{N}$} & \multicolumn{5}{|c|}{$\begin{array}{c}\text { Poor nutrition } \\
\text { at } 6 \text { months follow-up } \\
{[\mathrm{n}=346(59 \%)]}\end{array}$} \\
\hline & & $\mathrm{n}$ & $(\%)$ & POR & $(95 \% \mathrm{CI})$ & $\mathrm{P}$ \\
\hline & & & & & & \\
\hline Normal (24-30) & 204 & 78 & (38) & 1.00 & & \\
\hline$<24$ & 362 & 250 & (69) & 3.22 & $(2.22-4.68)$ & $<0.001$ \\
\hline Not known & 19 & 18 & (95) & 26.5 & $(3.46-203.4)$ & 0.002 \\
\hline IADL & & & & & & \\
\hline No difficulties (8) & 91 & 25 & (28) & 1.00 & & \\
\hline Difficulties (0-7) & 486 & 316 & (65) & 4.20 & (252-7.00) & $\varangle .001$ \\
\hline Not known & 8 & 5 & (62) & 4.24 & $(0.93-19.3)$ & 0.062 \\
\hline Basic ADL & & & & & & \\
\hline No difficulties (6) & 195 & 69 & (35) & 1.00 & & \\
\hline Difficulties (0-5) & 382 & 272 & (71) & 4.10 & (281-5.97) & $\varangle .001$ \\
\hline Not known & 6 & 5 & (62) & 3.12 & $(0.71-13.6)$ & 0.130 \\
\hline GDS-15 & & & & & & \\
\hline No depression (0-6) & 463 & 246 & (53) & 1.00 & & \\
\hline Depressed (> 6) & 96 & 75 & (78) & 2.94 & $(1.74-4.96)$ & $<0.001$ \\
\hline Not known & 26 & 25 & (96) & 20.5 & $(2.74-153)$ & 0.003 \\
\hline EMS & 554 & & & 0.77 & $(0.72-0.82)$ & $<0.001$ \\
\hline TUG time & 489 & & & 1.07 & $(1.05-1.09)$ & $<0.001$ \\
\hline TUG & & & & & & \\
\hline Normal (1-2) & 164 & 62 & (38) & 1.00 & & \\
\hline Moderately abnormal (3-4) & 269 & 146 & (54) & 1.83 & $(1.22-2.73)$ & 0.003 \\
\hline Markedly abnormal (5) & 41 & 38 & (93) & 18.7 & $(5.52-63.5)$ & $<0.001$ \\
\hline Not known & 109 & 100 & (92) & 16.3 & $(7.66-34.8)$ & $<0.001$ \\
\hline Grip strenght, better hand & & & & & & \\
\hline Normal (men $\geq 26 \mathrm{~kg}$, women $\geq 16$ kg) & 253 & 126 & (50) & 1.00 & & \\
\hline Weakened $($ men $<26 \mathrm{~kg}$, women $<16 \mathrm{~kg}$ ) & 332 & 220 & (66) & 1.81 & $(1.28-2.54)$ & 0.001 \\
\hline
\end{tabular}

Age-adjusted univariate analyses were performed by logistic regression results shown by prevalence odds ratios (POR) or by incidence odds ratios (IOR) with 95\% Confidence Intervals (CI). 
Supplementary Table. Attendees vs. non-attendees (N=958) at 6-month follow-up.

\begin{tabular}{|c|c|c|c|c|c|c|c|}
\hline \multirow[b]{2}{*}{ Age, Md (IQR, Range) } & \multicolumn{2}{|r|}{$\begin{array}{c}\text { Attendees } \\
(\mathrm{n}=585)\end{array}$} & \multicolumn{2}{|c|}{$\begin{array}{c}\text { Non-attendees } \\
\quad(\mathrm{n}=191)\end{array}$} & \multicolumn{2}{|r|}{$\begin{array}{c}\text { Deceased } \\
\mathrm{n}=182)\end{array}$} & \multirow{2}{*}{$\begin{array}{c}\mathrm{p} \\
<0.001\end{array}$} \\
\hline & 83 & $(77-87 ; 65-99)$ & 85 & $(81-90 ; 65-99)$ & 87 & $(83-91 ; 67-103)$ & \\
\hline Male, n $(\%)$ & 142 & $(24)$ & 55 & (29) & 59 & $(32)$ & 0.073 \\
\hline BMI, Md (IQR) & 25.8 & $(22.9-29.1)$ & 23.7 & $(21.2-27.0)$ & 24.5 & $(21.5-27.7)$ & $<0.001$ \\
\hline MNA-SF before hip-fracture, Md (IQR, Range) & 12 & $(10-13 ; 2-14)$ & 11 & $(9-12 ; 4-14$ & 10 & $(9-12 ; 4-14)$ & $<0.001$ \\
\hline Fracture type, $\mathrm{n}(\%)$ & & & & & & & 0.068 \\
\hline Neck of femur & 374 & $(64)$ & 105 & $(55)$ & 110 & $(60)$ & \\
\hline Intertrochanteric & 182 & (31) & 67 & $(35)$ & 62 & (34) & \\
\hline Subtrochanteric & 29 & $(5)$ & 19 & (10) & 10 & (6) & \\
\hline $\mathrm{ASA}, \mathrm{n}(\%)$ & & & & & & & $<0.001$ \\
\hline $1-2$ & 114 & $(20)$ & 21 & $(11)$ & 4 & $(2)$ & \\
\hline 3 & 374 & $(64)$ & 128 & $(67)$ & 98 & $(54)$ & \\
\hline $4-5$ & 90 & (15) & 42 & (22) & 77 & $(42)$ & \\
\hline missing & 7 & (1) & 0 & $(0)$ & 3 & (2) & \\
\hline Number of regularly taken medications, $\mathrm{n}(\%)$ & & & & & & & $<0.001$ \\
\hline$<4$ & 140 & $(24)$ & 31 & $(16)$ & 8 & (4) & \\
\hline $4-10$ & 360 & $(62)$ & 119 & $(62)$ & 117 & $(65)$ & \\
\hline over 10 & 85 & (15) & 41 & $(22)$ & 56 & (31) & \\
\hline Diagnosis of memory disorder, $\mathrm{n}(\%)$ & 152 & (26) & 59 & (31) & 59 & (32) & 0.318 \\
\hline Independent mobility, $\mathrm{n}(\%)$ & 390 & (64) & 80 & (42) & 45 & (25) & $<0.001$ \\
\hline Living in own home, $\mathrm{n}(\%)$ & 463 & (79) & 124 & $(65)$ & 86 & (47) & $<0.001$ \\
\hline Time to operation $<24 \mathrm{~h}, \mathrm{n}(\%)$ & 258 & (44) & 77 & (40) & 61 & (34) & 0.092 \\
\hline Hospital stay, n (\%) & & & & & & & $<0.001$ \\
\hline $1-3$ days & 44 & (7) & 8 & (4) & 9 & $(5)$ & \\
\hline 4-5 days & 292 & $(50)$ & 111 & (58) & 66 & (36) & \\
\hline 6-7 days & 181 & (31) & 49 & (26) & 56 & (31) & \\
\hline over 7 days & 68 & (12) & 23 & (12) & 36 & (20) & \\
\hline missing & 0 & $(0)$ & 0 & $(0)$ & 15 & (8) & \\
\hline MNA-SF before hip fracture, $\mathrm{n}(\%)$ & & & & & & & $<0.001$ \\
\hline Normal & 358 & $(61)$ & 83 & (44) & 52 & $(29)$ & \\
\hline At risk of malnutrition & 194 & (33) & 90 & (47) & 104 & (57) & \\
\hline Malnourished & 33 & $(6)$ & 18 & (9) & 26 & (14) & \\
\hline
\end{tabular}

Md=Median; IQR=Interquartile range. Differences (p-value) between groups were tested by independent samples Kruskall-Wallis test, Pearson chi-square test or Fisher's exact test. 
Figure 1

\section{0-2014}

$\mathrm{N}=1025$

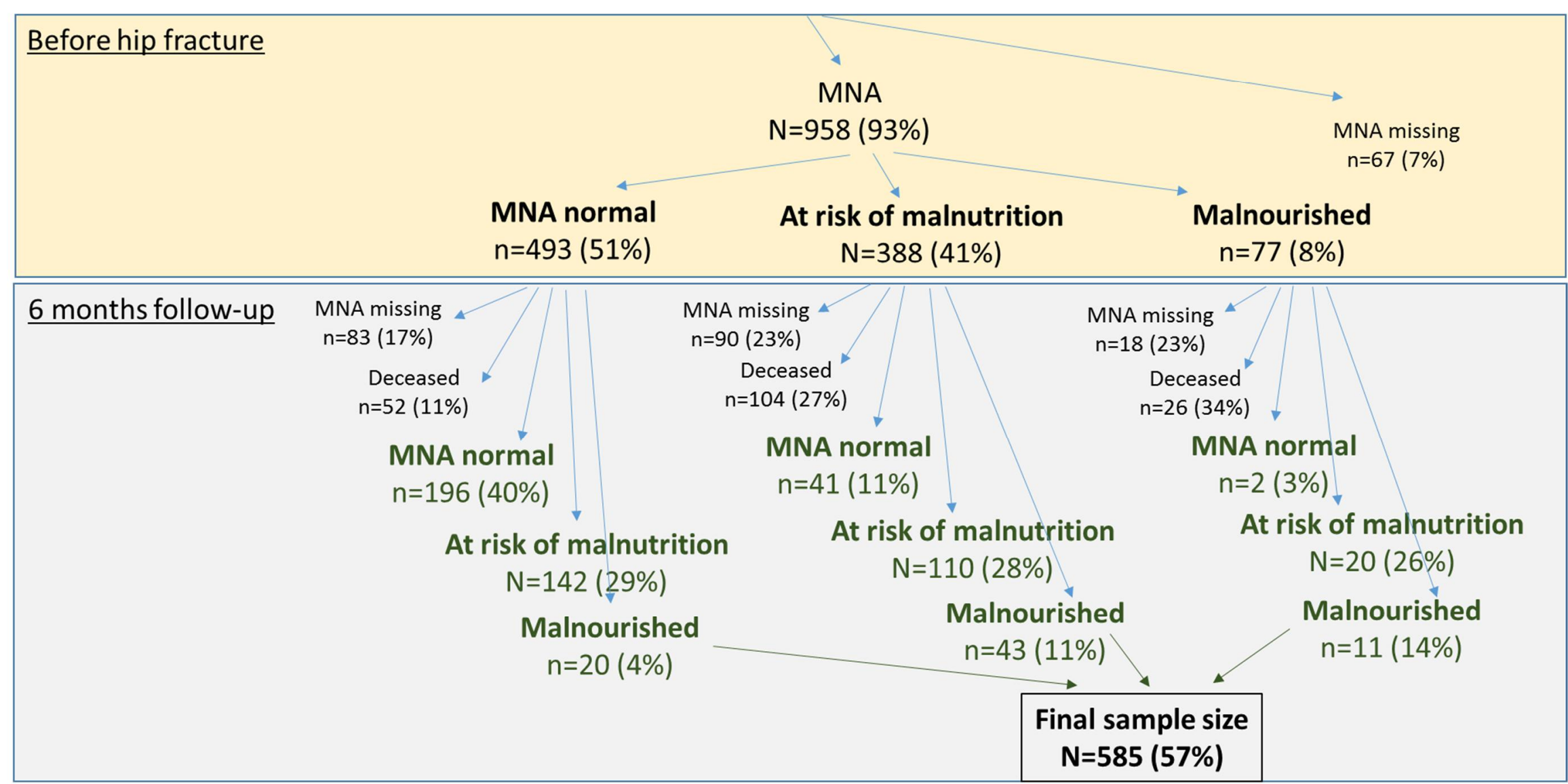

